\title{
EL DECLIVE DE LA ESCUELA MODERNA Y SUS RITUALES: ¿hay lugar para la memoria del pasado reciente argentino?*
}

\author{
THE MODERN SCHOOL AND ITS RITUALS: is there a \\ place for the memory of Argentinian's recent past?
}

\author{
Diego M. Higuera Rubio**
}

\begin{abstract}
Resumen
El articulo analiza qué ocurre en las escuelas argentinas con la implementación de los actos escolares sobre la última dictadura y cuál es su papel en el proceso de construcción de la memoria de los jóvenes. Con base en material de campo recolectado en dos secundarias públicas de la Ciudad de Buenos Aires, el articulo muestra que gran parte de los actos sobre la dictadura reproducen viejas premisas de la cultura escolar, lo cual limita la transmisión creativa de la memoria aunque no impide que deje "marcas" en las nuevas generaciones. El documento inicia con una síntesis teórica basada en ideas de F. Dubet y trabajos acerca de actos escolares e historia de la educación argentina, luego presenta el análisis de un acto y entrevistas a docentes y alumnos. Finalmente, subraya los dilemas que genera la articulación entre la transmisión de la memoria y el cuestionamiento que enfrentan las prácticas escolares en el mundo contemporáneo.
\end{abstract}

Palabras-clave: Rituales escolares. Memoria. Ciudad de Buenos Aires. Etnografía escolar.

\section{Resumo}

O declínio da escola moderna e seus rituais: há lugar para a memória do passado recente argentino?

Este artigo analisa o que ocorreu nas escolas argentinas com a implantação das comemorações escolares sobre a última ditadura e qual é o seu papel no processo de construção da memória de jovens. Com base no material de campo de duas escolas públicas secundárias da cidade de Buenos Aires, o artigo mostra que grande parte das comemorações sobre a ditadura reproduzem velhas premissas da cultura escolar, a qual limita a transmissão criativa da memória mas não impede que se deixem marcas nas novas gerações. $O$ artigo inicia com uma síntese teórica baseada nas ideias de F. Dubet e trabalhos sobre comemorações escolares e história da educação argentina. Em seguida, apresenta a análise de uma comemoração e entrevistas com docentes e alunos. Finalmente, destaca os dilemas que geram articulação entre transmissão da memória e o questionamento sobre as práticas escolares no mundo contemporâneo.

Palavras-chaves: Rituais escolares. Memória. Cidade de Buenos Aires. Etnografía escolar.

\begin{abstract}
This article examines what has happened in Argentinian schools with the implementation of school celebrations regarding the last dictatorship, and their role in the process of creating a memory for the youngsters. Based on field research material collected from two public high schools in the city of Buenos Aires, the present paper demonstrated that a significant part of the celebrations regarding the dictatorship reproduce old premises of the school culture, which limits the creative transmission of memory, but still leaves marks on the newer generations. The article begins with a theoretical review based on the ideas of F. Dubet and on previous works about school celebrations and Argentine's educational history. In the sequence, it presents an analysis of a particular celebration and interviews with teachers and students. Finally, it highlights the dilemmas that create links between memory transmission and the questioning of school practices in the contemporary world.
\end{abstract}

Keywords: School rituals. Memory. City of Buenos Aires. School Ethnography.

\footnotetext{
* Este artículo hace parte de una investigación más amplia que adelanté en los cursos del último año de la secundaria, cuyos principales hallazgos se encuentran en el documento 'Lo que todos sabemos, ¿no?'. Jóvenes y memoria. Las representaciones sobre la última dictadura argentina en la escuela", Tesis de Maestría, FLACSO-Sede Buenos Aires, 2008. Dirigida por la Dra. Inés Dussel.

** Doctorando - Universidad de Buenos Aires. E-mail: diegohig@yahoo.es
} 


\section{Introducción}

En los últimos años dentro del campo de la educación, se ha discutido hasta qué punto la escuela moderna y sus rituales han perdido capacidad de acción sobre los sujetos. Algunos autores señalan que la potencia de la escuela se ha visto seriamente afectada debido a la profundización de las contradicciones entre los valores fundantes de la modernidad (libertad/igualdad), el avance de los procesos de individualización, los cambios de las instituciones educativas y su papel en la distribución de capital cultural en el marco de las transformaciones socioeconómicas de los últimos treinta años. Incluso, algunos autores han afirmado que el sistema escolar está sumergido en una crisis terminal ${ }^{1}$. Para quienes abordamos los temas vinculados con la entrada del 'pasado reciente'2 en las escuelas argentinas resulta

\footnotetext{
1 Desde 1968, la palabra crisis adquirió relevancia en el campo educativo con el famoso trabajo de P. Coombs, "La crisis mundial de la educación", en el cual planteaba que el sistema escolar ya no era suficiente para la enseñanza sistemática y la integración de la humanidad; además, era incapaz de incorporar en su estructura los constantes cambios generados por la sociedad industrial. Con base en las ideas de Coombs y con el apoyo de UNESCO, se realizó en Estados Unidos una conferencia internacional que impulsó la corriente de Educación no formal y, a su variante europea, la educación social. Por esa época, desde una crítica radical al sistema capitalista, autores como Ivan Illich señalaban que la escuela estaba en una crisis terminal porque esa institución y sus integrantes eran incapaces de cumplir con la promesa educadora/liberadora. Hacia los años ochenta, con la proliferación de ideas y discusiones acerca de la 'postmodernidad', la escuela fue interpretada desde el prisma de la crisis de la modernidad. Hoy día, algunos autores encuentran que el uso indiscriminado de la palabra crisis para referirse a los diversos asuntos del mundo contemporáneo, ha desgastado la palabra de tal manera que su aplicación a la escuela resulta poco específica y de escaso potencial explicativo (ANTELO, 2003, p. 27). Ahora se habla de 'la educación en tiempos de crisis' (FERNÁNDEZ, 2001) o se presenta la cuestión en términos concretos, por ejemplo, la interrelación entre la crisis de sentido del EstadoNación y la escuela (NARODOWSKY; BRAILOVSKY, 2005, p. 148). El debate continúa pues investigaciones reconocidas exploran las consecuencias de 'la crisis', hasta el punto de afirmar que la escuela sólo conserva 'restos' de aquélla institución que conocimos hace unas décadas (DUSCHATZKY, 2007, cap. 3). Por otra parte, autores como Finocchio (2009, Introducción y cap. 5), señalan que el tema de la crisis no es nuevo, incluso, en el ámbito local circulaba entre maestros y educadores desde los años 60. Para esta autora, la escuela acumula más logros que fracasos y aunque el discurso de la crisis tiene algún asidero, no ofrece una mirada completa. En este sentido, Viñao (2002) afirma que las transformaciones obedecen a una progresiva 'escolarización' de aquellos ámbitos de socialización y formación ajenos al sistema educativo. No estamos ante el fin de la escuela, de hecho, se presenta el reforzamiento de algunas de sus características y funciones bajo el disfraz de una crisis encubierta (lbíd., p. 13). Solo puedo esbozar algunas líneas del debate; para efectos del presente escrito, me valdré de la perspectiva desarrollada por François Dubet sobre el declive de la institución escolar y la articularé con trabajos que abordan la crisis de los actos escolares en la Argentina.

${ }^{2}$ Esta categoría es objeto de un debate álgido entre los historiadores. En Argentina, debido al paso del tiempo y las discusiones académicas, la expresión 'pasado reciente' tiende a englobar de manera ambigua y general una serie de acontecimientos y procesos históricos diversos. En este texto el pasado reciente se refiere a la década del setenta y ochenta, con especial referencia a los temas relacionados con la última dictadura militar.
}

de especial interés analizar, a luz del debate sobre las transformaciones de la escuela en el mundo contemporáneo, qué ocurre con la implementación de los actos escolares sobre la última dictadura y cuál es su papel en el proceso de construcción de las memorias de los jóvenes que asisten a ellas.

En este documento analizaré información procedente del trabajo de campo realizado, entre el año 2004 y 2005, en dos secundarias públicas de la ciudad de Buenos Aires que atienden a sectores medios heterogéneos. El trabajo involucró observación de actividades en aulas y patios, entrevistas semiestructuradas con alumnas y alumnos de último año de secundaria y sus docentes de historia y educación cívica ${ }^{3}$. Acá retomaré la observación de un acto escolar y apartados de las entrevistas con docentes y alumnos en los que se aborda el tema de los actos escolares; además, introduciré elementos de otros ejes temáticos de las entrevistas donde los alumnos exponen, desde su perspectiva, un relato sobre el pasado reciente del país y algunas respuestas a preguntas sobre las clases de historia.

Iniciaré la exposición con una síntesis conceptual sobre los actos escolares y su implementación en el país a comienzos de siglo XX. Luego señalaré, retomando algunas nociones teóricas, que los actos han sufrido un desgaste como resultado de los cambios en las relaciones intergeneracionales y el proceso de declive institucional de la escuela moderna. Desde ese panorama general, iniciaré el análisis de lo que ocurre con la implementación de los actos sobre el pasado reciente en las escuelas visitadas. A través del análisis del material empírico mostraré que los actos escolares sobre la dictadura, aunque despiertan gran interés entre los chicos, se han cargado de los problemas que enfrentan los actos tradicionales porque su organización se realiza bajo las viejas formas de la cultura escolar. Buena parte del rechazo que los jóvenes manifiestan hacia los actos escolares, tiene que ver con la supervivencia de formas rituales estereotipadas, autoritarias y homogeneizadoras ligadas al modelo del sujeto pedagógico de comienzos de siglo XX. No obstante, las entrevistas con alumnos dejan en evidencia que los actos aún pueden incidir en la formación de su perspectiva sobre el pasado. Finalmente, subrayaré los dilemas que genera la articulación entre la transmisión de la memoria y el cuestionamiento que enfrentan las prácticas escolares en el mundo contemporáneo.

\footnotetext{
${ }^{3}$ En la escuela 1 entrevisté 19 alumnos pertenecientes a dos divisiones de la jornada mañana y 12 de una división de la jornada tarde. Entrevisté a la titular de historia de la jornada mañana y la educación cívica de las dos jornadas. En la escuela 2 entrevisté a 19 alumnos pertenecientes a dos divisiones. Trabajé con la coordinadora del área de historia y una docente de historia.
} 
Debo advertir que el análisis y conclusiones presentados a continuación, constituyen un aporte a la compresión de lo que ocurre en las escuelas con respecto al pasado reciente y no deben tomarse como hipótesis generales, dado que existen grandes diferencias entre las escuelas según su jurisdicción y perfil institucional ${ }^{4}$.

\section{Los actos escolares y las transformaciones de la escuela moderna}

Si analizamos los actos escolares según su forma y contenido, podemos considerarlos básicamente como un evento ritual: demandan una minuciosa preparación, tienen estrictas prescripciones temporales y espaciales, siguen una secuencia de ejecución e involucran elementos que son considerados sagrados por la sociedad. Dependiendo de los contextos culturales e históricos, los rituales se llevan a cabo en diferentes momentos y con diversos fines, desde la resolución de una crisis al interior de los grupos y la renovación de los lazos sociales, hasta los cambios de status de las personas durante el transcurso de su vida.

En un bello artículo, Madeleine Grumet (1997) muestra cómo los rituales tienen la capacidad de generar sentimientos comunes entre los participantes dado que los involucra en sus dimensiones cognitivas, emocionales y corporales. El ritual ubica en el mismo plano a diferentes personas que comparten una danza, un canto o una marcha, allí sus cuerpos se funden dentro del movimiento colectivo. Lo que ocurre en ese momento "no es ni una persuasión del intelecto ni una seducción de los sentidos... es el movimiento envolvente de todo el drama en el alma del hombre. Nos rendimos y somos cambiados". (GEERTZ, 1992, p. 65). El carácter 'envolvente' de los rituales interpela a cada participante, lo involucra de manera total y lo incorpora al colectivo, de allí su capacidad para la transformación de los sujetos y la reproducción social.

Martha Amuchástegui (2000) expone cómo, en Argentina, los actos escolares fueron estrictamente regulados a comienzos del siglo XX con el objetivo de contribuir a la formación de un sentimiento de identidad nacional y el disciplinamiento de la población. Para esa época, los inmigrantes europeos y sus hijos contribuían de manera significativa al crecimiento demográfico del país, espacialmente, en la ciudad de Buenos

\footnotetext{
${ }^{4}$ Ana Pereyra (2007) señala, con base en los resultados de su tesis de doctorado que incluyó encuestas entre alumnos de secundarias públicas de Capital Federal y el Gran Buenos Aires, que existen diferencias muy importantes entre los alumnos de las dos jurisdicciones. Así mismo, en un trabajo preliminar a mi investigación, encontré significativas diferencias entre las escuelas públicas y las privadas de Capital.
}

Aires ${ }^{5}$. La inmigración era una de las soluciones, según el paradigma que Sarmiento estableció a mediados del siglo XIX, para la erradicación de la 'barbarie' del territorio nacional y la generación las condiciones que garantizarían en el futuro la consolidación de una república civilizada. Sarmiento consideraba que las austeras y trabajadoras familias protestantes del norte europeo, serían el reemplazo ideal de las poblaciones autóctonas y mestizas que no poseían las virtudes requeridas por el progreso. Los inmigrantes que desembarcaron en el país no correspondían con el prototipo esperado, la mayoría eran del sur, católicos, pobres y analfabetos. Ante los 'magros' resultados, los intelectuales y dirigentes políticos de finales de siglo reubicaron la barbarie en las masas heterogéneas y cosmopolitas de la ciudad. Desde esta perspectiva, consideraron que, una vez más, el futuro y unidad de la nación se encontraban en riesgo; los inmigrantes tenían que renunciar a sus lenguajes, héroes y costumbres. (DUSSEL, 2001).

El siglo XXinició con una campaña, denominada 'Cruzada patriótica', que se propuso instaurar un orden social basado en la incorporación de todos los habitantes por medio de su argentinización. Entre otras medidas, se decretó el servicio militar obligatorio para los hombres jóvenes, la formalización del sistema judicial unificado y la producción de una memoria nacional. (PUIGGRÓS, 1994, capítulos 3 y $4)^{6}$.

La escuela fue una pieza central de la cruzada patriótica debido a su reconocida capacidad en el disciplinamiento de las nuevas generaciones. El presidente del Consejo Nacional de Educación, José Ramos Mejía (1908-1912), implementó una serie de normativas y directrices con las que reglamentó meticulosamente los tiempos, espacios y acciones en las escuelas, desde el tamaño de los pupitres hasta la forma y contenido de las ilustraciones en las aulas. (AMUCHÁSTEGUI, 2000, p. 65). También se encargó de impulsar una educación patriótica, muy de moda por aquélla época entre los círculos intelectuales, inspirada en la tradición europea de celebrar los acontecimientos oficiales y las efemérides, así como los éxitos militares de los 'grandes hombres'. Esta historia monolítica, encarnada en el bronce de las estatuas y monumentos erigidos por todas las ciudades, tenía como objetivo explícito formar el espíritu patriótico del que carecía la amorfa masa inmigrante, como afirmaba Carlos Octavio Bunge.

\footnotetext{
${ }^{5}$ Entre 1860 y 1930 habían ingresadoal país seis millones inmigrantes; en 1914 , el $80 \%$ de los habitantes de la capital era inmigrante o hijo de inmigrante (cifras citadas en DUSSEL, 2001, p. 199).

6 Dentro de este proyecto nacional el modelo de escuela argentina, cuyas bases fueron ideadas por Sarmiento, planteaba un esquema que incluía a todos los sujetos y, al mismo tiempo, excluía radicalmente sus particularidades. Buscaba, entonces, una identidad nacional basada en la igualdad educativa en el marco de un proceso de homogeneización (DUSSEL, 2000).
} 
(AMUCHÁSTEGUI, 2000, p. 64-66). La biografía de la nación debía concentrarse en sus orígenes épicos, en las batallas y guerreros que le dieron vida, aquellos fundadores de los valores y principios que nutren el alma de la entidad trascendental. Los recién llegados tenían que aprender los detalles de estas narrativas para integrarse a la comunidad nacional y fundirse dentro de su destino común ${ }^{7}$.

Los actos escolares se adaptaron a la educación patriótica y su potencia ritual se enfocó en la iniciación de las nuevas generaciones al devenir de la república. Conmemoraciones que eran practicadas regularmente a finales del siglo XIX, como 'El día del árbol' de inspiración positivista, fueron borradas por el renovado calendario de fiestas patrióticas que incluía las celebraciones por la independencia, la revolución de mayo, los padres fundadores y el 'descubrimiento de América'. (DUSSEL, 2001, p. 203). El establecimiento y regulación de la ceremonia de Jura a la bandera en 1909, es un buen ejemplo de este proceso:

Art. 1ero. El 24 de mayo de cada año, los directores de las escuelas harán Jura de la Bandera Nacional a los niños que ingresen por primera vez al establecimiento, con toda la solemnidad que la importancia del acto requiere y con observancia, además de las disposiciones reglamentarias del Saludo a la Bandera.

Art. 2do. La ceremonia se realizará como sigue: Reunidos los niños con sus maestros, y si fuera posible, toda la escuela, una comisión de los mismos, designada de antemano, conducirá la bandera al sitio de honor, la presentará, y todos los niños puestos de pie y extendiendo el brazo derecho hacia la bandera, pronunciarán con naturalidad y sentimiento, la siguiente invocación: "¡La bandera blanca y celeste; Dios sea loado; no ha sido jamás atada al carro triunfal de ningún vencedor de la tierra. Que flamee por siempre como símbolo de la libertad, objeto y fin de nuestra vida; que el honor sea su aliento, la gloria su aureola, la justicia su imperio!"

Art. 3ero. La expresada ceremonia se ajusta al programa siguiente:

$1^{\circ}$. Himno Nacional.

$2^{\circ}$. Palabras alusivas al acto, pronunciadas por el director o uno de los maestros.

\footnotetext{
${ }^{7}$ Inés Dussel (2004) resume una lectura prototípica de los libros de texto de la primaria editados entre 1880 y 1930, para ejemplificar la lógica de la educación patriótica dirigida a los inmigrantes: "[...] una maestra charlaba con un niño y el niño le preguntaba "¿quién es ese señor que está ahí en la pared?". "Ese señor es San Martín, el padre de la Patria". "Ah, pero en mi casa yo no tengo ese cuadro, tenemos otro cuadro". "¿Y de quién es?", "no sé, se lo voy a preguntar a mi papá". La lectura tenía varias etapas. En su casa tenía a Garibaldi porque su padre era italiano, un republicano italiano que adoraba a Garibaldi, entonces la maestra le dice: "si vivís en Argentina, el padre de la Patria es San Martín, tenés que tener a San Martín. Señorita, le voy a decir a mi papá que tenemos que tener a San Martín" (Ibíd., p. 3).
}

30. "Saludo a la Bandera". (canto).

$4^{\circ}$. Marcha "Viva la Patria", cantada por todos los niños desfilando ante la bandera. ${ }^{8}$

La jura está dirigida a ciertas personas en un tiempo social y vital particular. Se realiza el 24 de mayo -justo un día antes del origen de la nación- y en él deben estar presentes todos los niños que ingresan por primera vez a la escuela. Este ritual marca el cambio de status de un grupo de personas y, al mismo tiempo, revitaliza a la comunidad escolar. Así, unos niños se transforman en alumnos mientras que los demás miembros de la escuela renuevan en su canto el compromiso adquirido años atrás. En un momento solemne, los alumnos se entregan con sentimiento y naturalidad "se ven colmado(s) por la conciencia de algo inconmensurable que los trasciende y no puede ser explicado en términos racionales". (MCLAREN, 1996, p. 108). Una trascendencia no tiene que ver con la esfera religiosa sino con la fe laica en la nación y sus instituciones. La reproducción de la comunidad escolar, el ingreso de nuevos alumnos, está íntimamente ligada a la reproducción de la nación. Ella es la fuente sagrada y la Bandera concentra su esencia, es el objeto del juramento, de los saludos y los cantos. La Bandera encarna el carácter invencible, eterno y justo de la nación, objeto y fin de la vida de sus integrantes. El juramento también renueva un compromiso perpetuo: el niño debe confirmarse antes de entrar al recinto sagrado de formación del ciudadanoargentino. Se requiere completasolemnidad y exactitud en la ejecución para establecer el vínculo de cada participante con la entidad sagrada. Desde luego, los gestos y técnicas militares presentes en los actos -la formación, el orden cerrado, la escolta de la bandera, etc.- obedecían a la lógica de ejecución de la cruzada la patriótica.

He querido detenerme un poco en los orígenes de los actos escolares porque en la actualidad, su lugar e importancia están siendo cuestionados. Algunos autores afirman que los actos están inmersos en una profunda crisis que se origina en su escasa capacidad de adaptación a los cambios sociales ocurridos en los últimos treinta años. Cecilia Olorón (2000) señala que las nuevas generaciones no se sienten interpeladas por los actos patrióticos, se muestran indiferentes 0 poco interesadas en ellos. Es como si después de tanto tiempo estuvieran 'desgastados'. Sólo les inspiran aburrimiento, sentencia. Amuchástegui (2000) agrega que la crisis de los rituales escolares no tiene que ver con la forma - aunque esta dimensión también se ha visto afectada- sino con la dificultad que tienen los docentes para otorgarles nuevos sentidos, en otras palabras, permanece una estructura sin contenidos en su interior, es una estructura vacía. Los actos se organizan con regularidad pero han

\footnotetext{
${ }^{8}$ Mayo 1ero. 1909, Circ. No. 48. Digesto escolar 1920, p. 524
} 
El declive de la escuela moderna y sus rituales: ¿hay lugar para la memoria del pasado...

ido perdiendo sus significados y ahora hacen parte de las rutinas intrascendentes de la cultura escolar; su configuración jerárquica y militarista les resta capacidad de acción sobre los niños y adolescentes que hoy acuden a las escuelas.

Según Olorón y Amuchástegui, esta situación se presenta por varios motivos. En principio, la estructura de los actos obedece al modelo de sujeto pedagógico ${ }^{9}$ de comienzos de siglo $X X$, que ha perdido vigencia frente a los cambios culturales $^{10}$ ocurridos desde los años sesenta, en especial, aquéllos que han traído la paulatina reducción de la distancia entre las generaciones (en el trato niño/adulto, alumno/docente) dentro de un contexto de relativa democratización de las sociedades y las relaciones entre sus miembros. Estas transformaciones derivaron en el rechazo a las jerarquías y las formas unilaterales de interacción, afectando los cimientos tradicionales de la autoridad adulta. En el caso de la Argentina, la expresión política de estos cambios llegó en un momento de escalada en el uso de la violencia y el advenimiento de la dictadura, la cual reprimió enérgicamente las expresiones culturales. Sin embargo, el 'aplazamiento' del cambio en las formas de relación entre adultos y jóvenes por el régimen de control imperante, no detuvo el crecimiento de la brecha generacional que empezó a manifestarse

\footnotetext{
9 El sujeto pedagógico se refiere, según Puiggrós (1994), a las múltiples articulaciones entre el educador, el educando y los saberes, tomando los términos educador y educando en un sentido amplio, referido a todos los sujetos sociales que enseñan y aprenden. Uno de los elementos más importantes de este concepto para la discusión que propongo, tiene que ver con su carácter relacional: el sujeto pedagógico no es un sujeto en sentido ontológico, se constituye en un sujeto mediador que surge del encuentro entre el educador y el educando donde cada uno trae sus características y habitus del espacio social del que proviene y éstas condicionan el acto de transmisión que se genera. Entonces, a comienzos de siglo la relación entre un "educando (inmigrante europeo, ateo, liberal) y el maestro argentino del 900 (católico, también liberal e incluso positivista, entrerriano)" (Ibíd., 1994, pp. 29-33), se entablaba con base en la vocación del docente, su autoridad y el conocimiento que éste traía para incluir al educando en la nación y 'la carrera del progreso'. A continuación veremos cómo las transformaciones de los últimos años y el avance de las contradicciones inherentes a la modernidad, han cambiado a los sujetos que llegan a las escuelas y la institución en la que se desenvuelven, por tanto, esta relación, el sujeto pedagógico, es muy diferente.

10 Según Margulis y Urresti (1998), los jóvenes argentinos de los años 60 y 70 crecieron durante el auge del Estado desarrollista, lo cual, les permitió descargarse de obligaciones económicas y ampliar sus actividades a otros ámbitos de participación en esferas culturales y políticas. En esa época 'de abundancia', la educación se consolidó como una vía para el ascenso social, las clases medias se ampliaron y los sectores populares tenían asegurado puestos de trabajo que les permitían acceder a buenas condiciones de vida con la expectativa de mejorar la condición de sus hijos. En este contexto, donde el protagonismo de los jóvenes aumentaba, ocurrieron en el mundo eventos de ruptura a nivel político y cultural, tales como la revolución cubana, el mayo del 68 en Francia o el movimiento hippie. Para los jóvenes estos cambios traían un quiebre con la generación de sus padres y la búsqueda de alternativas a la sociedad establecida y sus jerarquías.
}

de forma notoria después de la restauración del sistema de democracia representativa. En los debates actuales sobre educación, esta brecha suele visibilizarse mediáticamente bajo el rótulo de la 'indisciplina' estudiantil y en el ámbito académico se ha convertido en un eje de reflexión asociado con el tema de la autoridad docente ${ }^{11}$.

De hecho, la institución escolar y las relaciones entre sus miembros, están inmersas en sociedades crecientemente 'juvenilista(s)', "donde lo que vale y lo que corre es ser eternamente jóvenes, cuanto más adolescentes mejor, hay una desautorización de los viejos y de sus experiencias". (DUSSEL, 2004, p. 6). De este modo las relaciones intergeneracionales se horadan y la acción de la transmisión por parte de los adultos es fuertemente cuestionada, incluso por los discursos pedagógicos.

La crisis de los rituales escolares también se relaciona con una profunda transformación de la escuela moderna. Según François Dubet (2004), la modernidad del siglo XIX y la primera mitad del XX, asumió una forma escolar y un modo de socialización que se puede definir como un 'programa institucional'; esto es, "una estructura estable de la información cuyos contenidos pueden variar de manera infinita". (DUBET, 2004, p. 16-17). La instalación de esa estructura en la mayor parte del mundo, en medio de contextos culturales, ideológicos y políticos disímiles, se logró de diversas formas pero sin alterar sus características fundamentales. Dubet considera que las características del programa institucional pueden agruparse en cuatro ejes:

1. La escuela es edificada bajo el modelo de una ciudad ideal que se encuentra aislada de los elementos externos a ella y se define exclusivamente por un conjunto de principios y valores concebidos como sagrados, homogéneos y trascendentales. Ninguno de ellos precisa de justificación.

2. Los profesionales de la educación se definen fundamentalmente por su vocación y no por el oficio que desempeñan. Dado que su deber es iniciar a las nuevas generaciones en los principios y valores trascendentales (la ciencia, la razón, el progreso, la nación, etc.), su firme convicción en ellos es más importante que cualquier fortaleza profesional. Así, la autoridad y prestigio docente no emanan del individuo sino de su condición como representante de los principios universales.

\footnotetext{
11 En un artículo reciente, Danilo Martuccelli (2009) expone un análisis interesante sobre los diagnósticos con respecto a los problemas que enfrenta la autoridad docente; para él, se pueden clasificar en tres tipos: los que examinan el debilitamiento del rol docente por transformaciones institucionales; los que relacionan las respuestas de los alumnos con las actuales condiciones de evaluación escolar y selección social y, finalmente, los que analizan el cambio de las relaciones de poder entre las generaciones vinculado con la inédita legitimidad que han adquirido la cultura adolescente y juvenil de consumo de masas.
} 
3. Puesto que la escuela declara su completa adscripción a todo aquello 'fuera del mundo' y los docentes están completamente regidos por este principio institucional, sus programas deben protegerse de los 'desórdenes y pasiones del mudo' y privilegiar los conocimientos teóricos y abstractos. En la escuela, las experiencias personales y conocimientos prácticos no tienen el mismo valor. La separación entre sexos, los uniformes y la disciplina escolar son ejemplos de las estrategias que fueron implementadas para acentuar el quiebre entre el mundo exterior y el santuario laico.

4. El programa institucional supone que el entrenamiento del alumno en la disciplina y el uso de la razón, lo habilitan para ejercer su propia libertad como sujeto. Allí, no importan sus características previas, pues el sometimiento a las figuras universales lo liberarán. Esta socialización implicaba, entonces, una subjetivación.

Durante varias décadas este modelo resultó efectivo porque los docentes se encontraban investidos con una autoridad indiscutible dentro de un espacio libre de contaminaciones. A su vez, la vocación y los principios universales justificaban una organización relativamente simple basada en la disciplina, el orden jerárquico, la imposición y la homogeneización. Sin embargo, desde hace unos treinta años, estas fortalezas se han ido transformando en debilidades; las contradicciones de la modernidad se han vuelto en contra de su programa institucional y desde sus propios fundamentos emergen los problemas. Los valores y principios trascendentales impuestos de manera vertical han perdido su potencia en sociedades donde los pactos políticos y sociales a nivel local tienen cada vez mayor relevancia. En un mundo donde la individualización aumenta y se dan ciertos logros democráticos, los principios trascendentales empiezan a perder su vigencia frente a las situaciones particulares.

Además, los principios universales empiezan a mostrar que no hacen parte de un conjunto coherente de acción del que se derive el bienestar social para todos. En el caso de Francia, por ejemplo, es evidente que La Libertad, La Igualdad y La Fraternidad no son valores equivalentes que ineludiblemente se complementan. En los países de la periferia del capitalismo, las contradicciones se presentan con mayor fuerza dado que las sociedades muestran un mayor grado de fragmentación y sus instituciones responden más a tareas de contención social. En muchos países de América Latina esta situación fue casi una constante histórica, y en Argentina esta característica se acentúo de manera dramática durante las últimas décadas, como señala Guillermina Tiramonti (2001).

En medio de este proceso la cultura escolar no se impone con la misma efectividad y otras agencias, especialmente los medios masivos, llegan a todos los sectores sociales con propuestas más atractivas que disputan abiertamente su hegemonía. Sin principios trascendentales y el cuestionamiento de la cultura escolar, los docentes ya no están en su puesto por una vocación, tienen que demostrar su profesionalismo, tomar cursos de formación permanente, rendir exámenes y trabajar en equipo. La autoridad ya no es inherente al lugar que los individuos ocupan dentro de la estructura jerárquica, ahora deben ganársela a diario. De este modo, los muros que aislaban y protegían a la institución escolar comienzan a resquebrajarse.

El fin de la institución escolar como un santuario también se encuentra promovido por la masificación de la educación después de la segunda mitad del siglo $X^{12}$. La escuela comenzó a responder a la demanda de diplomas y esto alteró la relación con el saber. Su modelo pedagógico ha empezado a responder más a la lógica de la producción que a la transmisión de principios universales; al mismo tiempo, los factores que impulsan el crecimiento de la autonomía de los individuos en las sociedades contemporáneas, disminuyen de manera proporcional la capacidad de la escuela para actuar sobre ellos. La escuela "ya no sólo recibe alumnos, sino también niños y adolescentes que deben construirse de un modo autónomo y 'auténtico' [...] el viejo modelo de la formación ha sido ampliamente desestabilizado y la relación pedagógica se transforma en un problema porque los marcos ya no son tan estables y porque un gran número de alumnos y estudiantes ya no son, a priori, 'creyentes'. (DUBET, 2004, p. 26-27).

En síntesis, la pérdida de sentido de los rituales escolares surge como resultado de procesos que se refuerzan mutuamente, por un lado, los cambios culturales que han modificado las relaciones de autoridad entre las generaciones y, por otro, el declive del programa institucional que subyace a la escuela moderna.

No podemos obviar que esta convergencia ocurre dentro de un contexto local marcado por fuertes transformaciones en la estructura social y económica, acompañadas de una crisis del sistema de representación política. ¿Cómo se introduce la historia reciente en ese golpeado entramado institucional?, ¿qué formas adquieren sus rituales de conmemoración?, ¿qué relación establecen con el pasado los niños y jóvenes que cuestionan la autoridad docente?

\footnotetext{
12 Según el Ministerio de Educación Nacional (2008), desde mediados del siglo $X X$ la población escolarizada de jóvenes de 13 a 17 años de edad aumentó de 1.794 .123 jóvenes en 1960 a 3.241 .550 en 2001 . Esto equivale a un cambio del $45,9 \%$, del total de la población, al $85,2 \%$. En secundaria el crecimiento ha sido mayor: la tasa neta de escolarización pasó del $24 \%$ en 1960 al $71,5 \%$ en el año 2001.
} 
El declive de la escuela moderna y sus rituales: ¿hay lugar para la memoria del pasado...

\section{El pasado reciente y los rituales escolares}

Las entrevistas con los alumnos de las instituciones visitadas muestran que para ellos los actos escolares no tienen valor por sí mismos; una fecha en la que ocurrió un suceso de gran relevancia o murió una persona notable, no generan entusiasmo o interés porque sean objeto de conmemoración. En la escuela de hoy, la capacidad que tienen los actos para interpelar a los alumnos tiene que ver fundamentalmente con su ejecución y no con sus aspectos rituales. En palabras de una docente "Hay veces que se ponen a charlar, o pasan una canción que ellos conocen y se enganchan, o alguna representación... depende el público y qué es lo que organizaron" (el subrayado es mío). Por su parte, los jóvenes exponen su punto de vista con mayor claridad:

Con los actos el tema es que... uno escucha un par, pero como generalmente termina aburriéndose o no escucha o termina boludeando.

(Escuela 1. Leticia 5-2). ${ }^{13}$

El que más me gustó fue el último, en el que hice de locutora, el del 9 de julio, porque... se hizo como toda una mesa; normalmente en los actos no se actúa ni nada de eso, normalmente son chicos parados que leen alguna cosa y la gente se duerme y no escucha mucho... esta vez, pusimos así una mesa antigua y estaba sentado Belgrano, ¡bah!; un muchacho imitando a Belgrano, otro a San Martín... y en la mesa estaban discutiendo las bases de la independencia.

(Escuela 2. Antonela. 5-4).

En las escuelas visitadas se han llevado a cabo diferentes actividades en el marco de los actos vinculados con el pasado reciente (24 de marzo, Guerra de Malvinas, La noche de los lápices), tales como charlas alusivas en las aulas, conferencias con representantes de Organismos de Derechos Humanos y jornadas de reflexión. Las actividades programadas cambian de un año a otro de acuerdo con la disponibilidad horaria de los docentes y directores, el nivel de participación de los alumnos y el número de compromisos institucionales programados durante el año. Sin embargo, la mayor parte de los actos realizados hasta el momento, siguen las pautas básicas de organización y estructura de los actos escolares tradicionales. Voy a ejemplificar esta situación con un fragmento -algo extenso pero necesario- de una observación que hice del acto por La Noche de los Lápices ${ }^{14}$ en la escuela 1 :

\footnotetext{
${ }^{13}$ Los nombres originales de las instituciones, docentes y alumnos han sido cambiados para resguardar su privacidad.

${ }^{14}$ Este episodio se ha tomado como un ejemplo emblemático de la represión durante el último gobierno militar. Uno de los
}

Hacia las 7:45 estaba llegando a la escuela, parece que todos los alumnos estaban enterados del acto. Una vez ingresaban se ubicaban en la cancha de fútbol cinco junto a sus compañeros de curso. En medio de la abarrotada y bulliciosa cancha, el preceptor y la vicedirectora daban, en tono amable, indicaciones para separar grupos y ordenar filas; luego se ubicaron en el fondo de la cancha. Los demás profesores lo hicieron delante de los alumnos al costado derecho de la formación. A su izquierda, frente a un micrófono y unos parlantes, estaban los alumnos del Centro de Estudiantes encargados del acto, dos hombres y cinco mujeres. Empezaron a sonar por los parlantes las notas del himno de la escuela, miré hacia la cancha y la multitud de jóvenes se había convertido en una formación silenciosa con miradas al frente. Una docente cantaba en un tono bajo con algunos de sus colegas. Los alumnos prácticamente no abrían la boca, excepto los que se encontraban en el frente de la formación. Todos escuchaban en silencio, unos con las manos en los bolsillos, otros con las manos al frente, con posturas corporales no muy firmes, más bien relajadas. Los encargados del centro de estudiantes releían con ansiedad unas líneas que tenían anotadas en unos pequeños papeles [...].

Terminó la música. Uno de los jóvenes del Centro, vestido con pantalón y camisa negra, se acercó al micrófono: "Este día nos encontramos reunidos para recordar lo ocurrido en una madrugada de 1976, en la que sacaron de sus casas a un grupo de chicos que habían luchado por una causa justa", por esta causa -prosiguió- se habían enfrentado al poder de la dictadura militar. La mayoría fueron asesinados y para toda la sociedad quedó el testimonio de Pablo Díaz, quien dio a conocer los terribles hechos, "hoy nos reunimos para recordar lo ocurrido".

Después de la corta introducción anunció la entrada de la Bandera Nacional. Desde la puerta principal llegaron tres alumnos formados en una línea paralela, que intentaban mantener con una especie de paso marcial. Se ubicaron entre los docentes y el grupo de jóvenes que dirigían el acto. En el centro de la formación estaba un chico alto y robusto que portaba con firmeza y gran seriedad el estandarte de la Bandera, a su derecha una chica y a su izquierda un chico, de estaturas notablemente menores. El muchacho de negro anunció el Himno Nacional. Éste fue entonado por todos los profesores y, otra vez, uno que otro chico cantó, en especial, aquéllos pertenecientes a los primeros años. Los que estaban ubicados al fondo guardaron silencio.

sobrevivientes, Pablo Díaz, dio un largo testimonio en el juicio a las juntas y tuvo una participación muy relevante en la difusión de los hechos en instituciones educativas y medios masivos. En un interesante artículo, Federico Lorenz (2004) analiza cómo este episodio se convirtió en un emblema del terrorismo de Estado. 
Terminó el Himno bajo un sonoro aplauso. El moderador anunció las palabras de Juan. El otro joven, de largo cabello negro, se ubicó frente al micrófono. También estaba vestido de negro y se distinguía en su buzo el nombre del grupo de rock, Metallica. Leyó con tranquilidad un corto escrito de tintes poéticos, en el que se refería al infinito valor creativo de las palabras en contraposición al carácter destructivo de las armas "[...] ellas dan lugar al recuerdo, a la transmisión de eso que no podemos olvidar [...]". Los asistentes aplaudimos y luego el moderador anunció la lectura, a cargo de sus compañeras, de un texto sobre los acontecimientos ocurridos el 16 de septiembre.

Las jóvenes estaban formadas en fila y se iban relevando en la lectura del texto. Comenzó una chica de cabello negro y gruesos lentes, leía segura y pausadamente: "En la Ciudad de La Plata, durante la madrugada del 16 de septiembre comenzaron los secuestros de un grupo de chicos". El relato brindaba detalles sobre la forma como los represores los sacaron de sus casas, simplemente por pertenecer a un centro de estudiantes que había hecho un reclamo justo: el boleto estudiantil. El relato subrayaba el tormento al que habían sido sometidos los jóvenes por haber hecho un reclamo, esto mostraba la ferocidad de la dictadura y su enorme injusticia "[...] sobrevivieron unos pocos y Pablo Díaz contó lo ocurrido [...] tenemos que recordar para que no vuelva a ocurrir [...]". La quinta joven terminó el relato de los hechos y la última leyó un fragmento que subrayaba enfáticamente los motivos del acto: "recordar a unos jóvenes que lucharon por una causa justa, de un centro de estudiantes, como nosotros. Debemos reivindicar esa lucha". Un aplauso acompañó el final de los casi quince minutos de lectura.

La atención de los asistentes no fue completa. Mientras las jóvenes leían terminaron de llegar varios alumnos que se ubicaron cerca de la entrada, atrás de los profesores. En un momento empezaron a charlar, a tal punto que una docente les llamó la atención -“¡bueno!...”- dijo en voz baja y con una clara expresión de disgusto en su rostro. Podía escuchar otros murmullos que provenían de las últimas filas, algunos profesores a mi lado oteaban con el seño fruncido $[. .$.$] .$

Terminada la lectura de los acontecimientos, el joven con la camiseta de Metallica tomó el micrófono para cerrar el acto: "Este día hacemos memoria de lo ocurrido, porque en democracia es la única forma de construir una sociedad justa". Su compañero anunció la salida de la bandera y vinieron los aplausos. Para el cierre "las palabras de la señora vicedirectora", quien emergió del fondo de la cancha. Mientras salía se escuchaban unos silbidos tenues y uno que otro ¡buuu!, que corría por debajo de las filas, causando sonrisas y carcajadas frustradas. Atrás escuché a una profesora que comentó en voz baja sonriendo, "¡son terribles!".

Mientras los cursos salían de la cancha, los parlantes emitían una marcha militar que retumbaba entre la tranquila y desordenada multitud de jóvenes que se dirigía a las aulas para iniciar las clases. “i¿Quién puso eso?!”, le pregunté a una docente de historia, que me respondió sonriendo "¡no sé, pero es muy paradójico en un acto como éste!".

Este acto sintetiza los efectos de la inclusión de los temas relacionados con la dictadura dentro de actos regulados bajo las pautas tradicionales de la cultura escolar: se realizan bajo las formas establecidas por los actos patrióticos. Solemnidad, orden cerrado y pasos marciales enmarcan las proclamas contra del autoritarismo y su barbarie. No obstante, la apatía de los alumnos frente al acto presenta diferencias importantes con respecto a los otros. El Centro de Estudiantes estuvo encargado de la organización y muchos asistentes permanecieron atentos. Como dije antes, la capacidad de convocatoria del acto no depende de su estructura sino del interés que los alumnos depositan en los temas tratados y las actividades que se realizan durante el evento. En las dos escuelas, los alumnos se refirieron a la dictadura como un momento de gran relevancia y se mostraron muy interesados en lo que la escuela pueda transmitirles al respecto, pues consideran que en ese espacio de saber tendrán acceso a una versión completa de lo ocurrido, sin todos los silencios y ambigüedades presentes en las memorias de los adultos. (HIGUERA, 2009). Por ello, la perspectiva de los jóvenes acerca de los actos que tratan el pasado reciente tiene diferentes matices.

La mayor parte de los entrevistados utiliza expresiones positivas para describir los actos y sentar su posición frente a ellos. Estas respuestas podrían clasificarse en dos grupos, por un lado, las que dan cuenta de la 'eficacia' de los rituales escolares y, por otro, las que muestran su capacidad para 'instalar' el tema. Con el término 'eficacia ritual' aludo a los jóvenes que reivindican la importancia de los actos, participan en su organización, pueden explicar sus contenidos y, en algunos casos, reflexionan a partir de ellos:

$\mathrm{E}:[\ldots]$ se hacen todos los eventos conmemorativos, empezando por el 24 de marzo, que es el día del golpe militar [...] eh, hay uno que también es importante para mí... bah... para todos los estudiantes que es el de La noche de los lápices [...]

D: ¿Por qué?

E: Un grupo de estudiantes que se une para pedir algo [...] [además] nos involucra a nosotros, a todos los estudiantes... ver cómo en el pasado, además en 
El declive de la escuela moderna y sus rituales: ¿hay lugar para la memoria del pasado...

el contexto en donde hicieron ese reclamo, el boleto estudiantil, tener un pasaje más barato para todos los estudiantes, me parece que es importantísimo.

(Escuela 1. Ernesto 5-2).

[...] participo en los actos, por ejemplo, en los últimos años estuve escribiendo para los actos... y... bah, para ese [el del 24 de marzo] y para La noche de los lápices [...] Pasó en la dictadura, el 16 de septiembre del 76, eh... unos chicos que estaban pidiendo por el boleto estudiantil, cinco centavos, los secuestraron y los desaparecieron, salvo uno que lo liberaron para que contara todo... eran todos del centro de estudiantes de La Plata... y, nada, bueno ese también se conmemora [...] es uno de los que más me llega a mí... a parte porque un par de años, yo iba a un par de marchas así por el boleto estudiantil.

(Escuela 1. Eva 5-6).

Con la expresión 'instalación del tema' me refiero a los jóvenes que comparten interés en los actos y los reivindican, pero no logran exponer mayores comentarios sobre ellos y tampoco los pueden vincular con sus reflexiones o los demás temas abordados durante la entrevista. De hecho, en algunos casos las referencias a los actos se formulan de manera descontextualizada y confusa. Por ello, utilizo la palabra 'instalación': los actos ubican un título dentro de la memoria transmitida:

L: [...] después, también, La noche de los lápices que es el golpe del $76<$ sic $>$

D ¿Qué pasó ahí?

L: Es lo que secuestraban a la gente todo eso... $<$ silencio>

D: ¿Qué hacen en ese acto, te acuerdas más o menos?

L: Sí, sí... o sea, hablan todo eso del... de los secuestros, cuentan casos, a veces los chicos se ponen a investigar un poco... cuentan algunos casos de la gente, algunos testimonios... este... bue... no me acuerdo más.

(Escuela 1. Leandro 5-4).

Últimamente estuvieron haciendo las fechas de... La noche de los lápices [...] fue cuando estaba, este... un milico en el poder... este... ay... ¿cómo se llama?... no me acuerdo ahora, no me acuerdo quien estaba [...] me parece interesante sí, saber de nuestra historia para que no se vuelva a repetir.

(Escuela 1. Laura 5-6).

S: los actos de los golpes... el golpe militar

D: ¿Cuáles golpes?

S: Que hubo 30 mil desaparecidos, no sé si acuerda...
D: No, cuéntame ¿cómo fue?

S: No pará, no sé mucho... hace un montón, que hubo un golpe militar y que desaparecieron a 30 mil personas y bueno... hay un grupo de estudiantes que organizan actos.

(Escuela 2. Sergio 5-1).

Este tipo de respuestas, que he traído a manera de ejemplo, aparecen en las entrevistas de las dos escuelas e indican que la eficacia ritual de los actos ha perdido potencialidad. Sin embargo, es notable que Sergio no mencionara el golpe de estado o los desaparecidos en su relato acerca de la historia reciente, mientras que al referirse a los actos el tema surgió de manera espontánea. No brindó mayores detalles, especificaciones temporales o marcos explicativos, pero la presencia de las conmemoraciones en su discurso y los motivos por los que se realizan, es un ejemplo de cómo los actos aún conservan cierta capacidad de acción sobre el joven, a pesar del rechazo que expresa hacia las formas escolares de transmisión del pasado: "es una materia que casi no me atrae la de historia, pero me la tengo que traer". Buena parte de las entrevistas están cargadas de este tipo de ambigüedades, donde los jóvenes 'saben' y 'no saben'; considero que es muy importante retomarlas para matizar las ideas procedentes de los análisis sobre la crisis de los actos escolares. Los problemas que atraviesan estas prácticas no implica que sus efectos se hayan diluido completamente: todavía algunos jóvenes participan de los actos y aún quienes los rechazan explícitamente muestran que han influido en la construcción de su perspectiva sobre el pasado. El análisis de las diferencias entre las dos instituciones visitadas, también apunta en este sentido: en la escuela 2, por cuestiones de espacio y tamaño, los actos se realizan de manera discontinua y, en general, no pueden asistir todos los alumnos. En la escuela 1, por el contrario, se presentan condiciones que permiten la organización regular de los actos referidos al pasado reciente; en ella, la mayor parte de los jóvenes los mencionó y pudo desarrollar respuestas más completas al respecto.

La identificación de la eficacia ritual de los actos escolares o su capacidad de 'instalar' acontecimientos, nombres o fechas en el horizonte simbólico de los chicos, nos permite afirmar que esta práctica no ha caducado plenamente, en especial, cuando su tema despierta interés en las nuevas generaciones. Así las cosas, surge la necesidad de formular otras preguntas relacionadas con los límites que esta práctica le impone a la transmisión de la memoria. Un joven de la escuela 1, que a lo largo de la entrevista mostró cierto manejo de algunos temas sobre el pasado reciente, lograba contextualizarlos 
y marcar procesos, no pudo exponer mayores comentarios cuando se refirió al acto por La Noche de los Lápices. En la entrevista expresó incomodidad con los actos sobre la dictadura y formuló algunas críticas que, si bien son erráticas, deben ser analizadas:

\begin{abstract}
M: [...] fue la noche que los estudiantes por medio del reclamo del boleto estudiantil fueron desaparecidos durante la época de la dictadura [...] eso es lo que yo sé... me van a matar, ¿no?... para el quinto año solamente eso y estuve en todos los actos [...] Un problema que tengo [con los actos], es que cuando me presentás algo para que me interese, no me va a interesar [...] por esto que investigar el tema me puede llegar a interesar más... me parece que muchas veces son muy cuadrados los actos, pese a que el tema es el mismo y obviamente no podés innovar mucho [...] Algo que no me gustó de los actos con el tema de la dictadura militar, es que la dictadura tuvo un montón de muertes y desapariciones... pero, también, lo que habría que aclarar, me parece, no justificando una acción, sino que también... los montoneros mataron gente inocente
\end{abstract}

\section{D: ¿Quiénes eran ellos?}

$E:$... y... eran gente que, por lo que se dice, estaban en contra de la... el servicio militar... eso está bien... ninguna de las dos acciones está justificada, pero me parece que para completar la historia también habría que contar eso.

\section{(Escuela 1. Mario 5-2. El subrayado es mío).}

Pese a su asistencia regular a los actos, Mario solo nombró el episodio, sus causas y el período en el que ocurrió. El ritual sitúa los acontecimientos dentro de una serie de eventos memorables pero su forma obstaculiza una apropiación reflexiva y creativa. Para Mario, todos los actos son iguales e invariables, cuestiona las prescripciones de la cultura escolar pero asume que los actos deben apegarse a ellas, sólo resta pensar en 'hacer algo más' ¿por qué no se puede innovar?, ¿existe sólo una manera de abordar los temas?, ¿por qué no se exponen discusiones o preguntas? El discurso unívoco de los actos genera malestar en el joven porque no habilita el planteamiento de sus inquietudes: me parece que para completar la historia también habría que contar eso. Mario alude a un período de violencia entre 'dos bandos' que conoce a través de 'lo que se dice', a partir de allí, se pregunta por qué se recuerda a unos muertos y a otros no. El acto no le ayuda a volver sobre sus dudas, llenar vacíos de información, buscar las incoherencias de su discurso y comparar de manera crítica las versiones contradictorias sobre el pasado que circulan en la sociedad.

Otra chica también manifestó inconformidad hacia a los actos pero, a diferencia de Mario, compara y valora otras actividades realizadas en la escuela pues considera que le han permitido abordar los temas de manera más completa y reflexiva:

[...] los actos que se hacen acá son mediocres... habla una chica, presenta la bandera de ceremonia, entra la bandera de ceremonia, cantamos el himno, cantamos el himno si es el día del maestro, si es día de las Malvinas... bueno, cantamos... después, el taller de periodismo preparó unas palabras para conmemorar la fecha y lee una piba, lee alguna profesora, dice algo la vicedirectora, se terminó el acto [...] La noche de los lápices siempre habla Pablo Díaz, siempre tenemos el mismo testimonio, todos los años... los chicos de primer año que entran y los chicos de quinto año que se van, siempre saben lo que dice Pablo Díaz [...] el único acto, que tengo así más... en mi primer año, hubo un acto [...] para La noche de los lápices... y ese acto me quedó grabado porque fue una jornada dedicada a La noche de los lápices y todos trabajamos... también la conmemoración del colegio, se hicieron dos días de jornada el viernes y sábado. (Escuela 1. Vanesa 5-2. El subrayado es mío).

La joven supone que todos los alumnos de los últimos cursos, al igual que ella, saben 'de memoria' lo que dice Pablo Díaz porque lo escucharon una y otra vez durante los cinco años de la secundaria. Si bien en la escuela 1 casi todos los entrevistados aludieron a los actos por el pasado reciente, no todos lo hicieron de la misma manera; alrededor de la mitad expusieron referencias muy escuetas como las ejemplificadas en los fragmentos citados antes. La repetición solemne no implica una reproducción exacta y homogénea como dice Vanesa; la apropiación de los actos se encuentra mediada por los antecedentes familiares y sociales de cada joven, así como por sus inquietudes personales y orientaciones profesionales. Vanesa se interesa por las humanidades y la historia, consulta libros y revisa artículos en diarios o revistas. Aunque sus padres tienen dificultades para abordar el tema de la dictadura, lo han hecho cuando se la menciona en los medios masivos o por inquietudes planteadas por Vanesa y sus hermanos. Ella puede reproducir 'de memoria' los actos y discursos, pero esta situación no es común a todos sus compañeros, sólo se presenta entre los chicos que comparten alguna de las características de Vanesa, bien sean intereses, conocimientos, contexto familiar, etc. ${ }^{15}$

\section{A modo de cierre}

En la actualidad, dentro del sistema educativo argentino, los actos sobre el pasado reciente han

\footnotetext{
${ }^{15}$ Las entrevistas también incluyeron preguntas sobre los intereses de los chicos y las 'fuentes' de sus relatos acerca del pasado reciente, en especial, las vinculadas con el ámbito familiar.
} 
El declive de la escuela moderna y sus rituales: ¿hay lugar para la memoria del pasado...

ganado un lugar relevante a nivel de las instituciones y la legislación, pese a las dificultades y resistencias asociadas con el abordaje de temas especialmente sensibles para los diferentes sectores de la sociedad. (HIGUERA, 2008). Sin embargo, las nuevas fechas en el calendario de conmemoraciones tienden a subordinarse a las antiguas pautas organizativas de los actos escolares, formuladas e implementas según la lógica autoritaria y solemne de la 'cruzada patriótica' de principios del siglo $\mathrm{XX}$, cuyo objetivo era el disciplinamiento y homogeneización de la población.

Las transformaciones institucionales que sufre la escuela moderna, el avance del proceso de individualización y los cambios socioeconómicos y de representación política a nivel local, hacen que las nuevas generaciones empiecen a cuestionar las formas tradicionales de los actos escolares. La convocatoria de este tipo de eventos ya no depende de sus formas rituales (orden cerrado, canto de himnos, exhibición de banderas, etc.) o el apego a las tradiciones, en este momento se encuentra ligada con el tipo de actividades realizadas en cada acto y los temas abordados. Como señalé, entre los jóvenes existe gran expectativa por el tratamiento del pasado reciente dentro de la escuela pues esperan recibir allí una versión cercana a 'la verdad', sin los silencios y contradicciones presentes en las memorias que agencian los adultos.

Tenemos, entonces, que la posición de los jóvenes frente a los actos vinculados con el pasado reciente, obedece a una tensión entre el generalizado interés que tienen por el tratamiento de la temática en la escuela y la crisis de las formas rituales de esta institución. Por ello, en las entrevistas y observaciones encontramos que los jóvenes asumen distintas posturas frente a estos actos, que van desde la completa indiferencia hasta la participación activa en su organización y ejecución. Entre los dos extremos se presentan distintos matices que muestran cómo el 'desgaste' de los rituales escolares no implica el fin de su capacidad de acción sobre los sujetos. Si comparamos la información recolectada en las dos escuelas visitadas, podemos llegar a una conclusión en el sentido: en la escuela 1, donde los actos se realizan con mayor regularidad que en la escuela 2, un número importante de alumnos describió con cierto detalle los actos, los motivos por los cuales se realizan y, en algunos casos, formularon reflexiones a partir de ellos. No obstante, las entrevistas también muestran que las formas de los actos escolares limitan la transmisión de elementos fundamentales para generar entre los jóvenes una apropiación del pasado compleja y menos estereotipada.

Podemos decir que los educadores disponen de una instancia que aún tiene capacidad de interpelar a sus alumnos, pero requiere la implementación de nuevas estrategias y articulaciones con las demás prácticas escolares. Las jornadas de reflexión, la organización de actos por los alumnos, el impulso a los Centros de Estudiantes y la organización de charlas alusivas, conforman una serie de alternativas que se vienen gestando e implementando desde el interior de las escuelas para modificar la lógica que subyace a los actos escolares. No obstante, los casos analizados muestran que las transformaciones avanzan con lentitud y sus alcances aún son modestos.

Frente a las continuidades de los actos escolares y su pérdida de sentido en el contexto actual, los educadores están obligados a replantear la lógica de estas prácticas de transmisión de la memoria. ¿Cómo se deberían modificar los actos para que adquieran nuevos significados para alumnos y docentes?, ¿cómo generar un sentimiento de comunidad y vínculo con el pasado sin repetir prácticas asociadas con las formas del autoritarismo?, ¿se pueden llevar a cabo rituales democráticos?, ¿qué acciones deben implementarse para habilitar la crítica? Considero quelaformulación de respuestas creativas a estetipo de interrogantes puede evitar que los aprendizajes del pasado se circunscriban a homenajes para los muertos y habilite la participación, la reflexión y, en últimas, el establecimiento de un vínculo vivo con el pasado, que le sirva a las nuevas generaciones para comprender su realidad e impulse la profundización de la democracia en el presente.

\section{Referencias}

ANTELO, E. Tarea es lo que hay. In: DUSSEL, I; FINOCCHIO, S. (Comp.). Enseñar hoy: una introducción a la educación en tiempos de crisis. Buenos Aires: Fondo de Cultura Económica, 2003. p. 27-34.

AMUCHÁSTEGUI, M. El orden escolar y sus rituales. In: GVIRTZ, S. (Comp.). Textos para pensar el día a día escolar. Buenos Aires: Editorial Santillana, 2000. p. 5977.

DUBET, F. ¿Mutaciones institucionales y/o neoliberalismo? In: TENTI, E. (Ed.). Gobernabilidad de los sistemas educativos en América Latina. Buenos Aires: IIPEUNESCO, 2004. p. 15-43.

DUSSEL, I. La producción de la exclusión en el aula: una revisión de la escuela moderna en América Latina. In: $X$ JORNADAS LOGSE. La escuela y sus agentes ante la exclusión social. Granada: España, 2000. p. 1-23.

Childhood and the politics of memory in Argentina. In: HULQUIST, K.; PAHLBERG, G. (Ed.). Governing the child in the new millennium. London: Routledge Falmer, 2001. p. 193-220.

Presentación de la perspectiva de las investigaciones realizadas por La FLACSO. Buenos Aires: Programa Nacional de Inclusión Educativa Todos a Estudiar. Jornadas de lanzamiento, Mimeo, 2004. 
DUSCHATZKY, S. Maestros errantes: experiencias sociales a la intemperie. Buenos Aires: Paidós, 2007.

FERNÁNDEZ, M. Educar en tiempos inciertos. Madrid: Morata, 2001.

FINOCCHIO, S. La escuela en la historia Argentina. Buenos Aires: Edhasa, 2009.

GEERTZ, C. Géneros confusos: la refiguración del pensamiento social. In: REYNOSO, C. (Ed.). El surgimiento de la antropología posmoderna. Barcelona: Gedisa, 1992. p. 63-77.

GRUMET, M. Restaging the civil ceremonies of schooling. The review of Education, Pedagogy and Cultural Studies, v. 1, n. 19, p. 39-54, 1997.

HIGUERA, D. La escuela como escenario de lucha por el pasado: reflexiones a partir de un caso de la Ciudad de Buenos Aires. Propuesta Educativa, Buenos Aires, n. 30, p. 109-116, 2008.

Memorias y sentidos comunes en la escuela: reflexiones sobre la enseñanza de la historia reciente argentina. Solta a Voz, Goiânia, v. 20, n. 2, p. 273-284, 2009.

LORENZ, F. Tómala vos dámela a mí. La noche de los lápices: el deber de memoria en las escuelas. In: JELIN, E.; LORENZ, F. (Ed.). Educación y memoria: la escuela elabora el pasado. Buenos Aires: Siglo XXI Editores, 2004. p. 95-129.

MCLAREN, P. La escuela como performance ritual. México: Siglo XXI, 1996.

MARGULIS, M.; URRESTI, M. Buenos Aires y los jóvenes: las tribus urbanas. Revista de Estudios Sociológicos, México, v. 16, n. 46, p. 25-35, 1998.

MARTUCCELLI, D. La autoridad en las salas de clase: problemas estructurales y márgenes de acción. Diversia, Valparaíso, n. 1, p. 99-128, abr. 2009.

NARODOWSKI, M.; BRAILOVSKY, D. La cuestión del fin de la razón de Estado en la historia de la escolarización. Cadernos de História da Educação, Uberlândia, v. 4, p. 143-154, 2005.

OLORÓN, C. Imágenes de unos rituales escolares. In: GVIRTZ, S. (Comp.). Textos para pensar el día a día escolar. Buenos Aires: Editorial Santillana, 2000. p. 79102.

PEREYRA, A. La relación de los adolescentes con la historia reciente de Argentina: un estudio exploratorio de la conciencia histórica entre estudiantes de escuelas medias públicas de la Ciudad de Buenos Aires. 2007. 369 f. Tesis (Doctorado en Ciencias Sociales) - Faculdade Latino-Americana de Ciências Sociais, Buenos Aires, 2007.

PUIGGRÓS, A. Sujetos, disciplina y currículo. Buenos Aires: Editorial Galerna, 1994.

TIRAMONTI, G. Modernización Educativa en los ‘90 ¿EI fin de la ilusión emancipadora? Buenos Aires: FLACSO/ Tema Grupo Editor, 2001.

VIÑAO, A. Sistemas educativos, culturas escolares y reformas: continuidades y cambios. Madrid: Morata, 2002.
Recebido em 15/03/2010

Versão final recebida em 30/07/2010

Aceito em 02/08/2010

Práxis Educativa, Ponta Grossa, v.5, n.2, p. 149-160, jul.-dez. 2010. Disponível em <http://www.periodicos.uepg.br> 